\title{
ASSESSMENT OF THE ENGLISH LITERACY LEVEL OF PATIENTS IN PRIMARY health care Services in Tshwane, Gauteng province: Part 2
}

\author{
Authors: \\ Zelda Wasserman \\ Todd M. Maja \\ Susanna C.D. Wright ${ }^{1}$
}

\begin{abstract}
Affiliations:
${ }^{1}$ Adelaide Tambo School of Nursing Science, Tshwane University of Technology, South Africa
\end{abstract}

Correspondence to: Susanna Wright

email:

wrightscd@tut.ac.za

Postal address:

Adelaide Tambo School of Nursing Science, Private Bag X680, Pretoria 0001, South Africa

\section{Keywords:}

English literacy levels; learning ability battery; literacy; primary health care; REALM-R

\section{Dates:}

Received: 18 June 2009

Accepted: 17 Feb. 2010

Published: 07 Sept. 2010

How to cite this article: Wasserman, Z., Wright, S.C.D. \& Maja, T.M., 2010, 'Assessment of the English literacy level of patients in primary health care services in Tshwane, Gauteng Province: Part 2' Health SA Gesondheid 15(1), Art. \#469, 6 pages. DOI: 10.4102/hsag.v15i1.469

This article is available at:

http://www.hsag.co.za

(c) 2010. The Authors.

Licensee: OpenJournals Publishing. This work is licensed under the Creative Commons Attribution License.

\section{ABSTRACT}

Low literacy can be described as the inability to read, write or use numbers effectively. The limited ability to read and understand health care instructions directly translates into poor health outcomes. The aim of this study was to assess the English literacy levels of primary health care patients using the Learning Ability Battery (LAB) and the adapted Rapid Estimate of Adult Literacy, Revised (REALM-R) and to determine how the results of the adapted REALM-R correlate with those of the LAB. Data were collected by means of a self-report whereby the participants had to answer the questions that were posed in the LAB and read the words out loud for the adapted REALM-R. The data analysis was performed by means of descriptive and inferential statistics, including the chi-square test and Spearman's rho. The result of the study indicated that in South Africa, school grades achieved and the reading levels of primary health care patients differ with four grades. In terms of the correlation between the results of the adapted REALM-R and those of the LAB, a correlation of $r=0.43(p<0.001)$ could be established. Depending on the cut-off point used for the adapted REALM-R, $67 \%$ of the participants had low literacy levels. The study provides evidence of the importance of a validated, quick and easy-to-administer literacy screening tool. The effective assessment of patients' literacy levels will assist registered professional nurses to provide health education on an appropriate level to improve patients' health literacy.

\section{OPSOMMING}

Lae geletterdheidsvlakke kan beskryf word as 'n persoon se onvermoë om doeltreffend te lees, te skryf of syfers te gebruik. Die beperkte vermoë om te lees en gesondheidsorgvoorskrifte te verstaan, gee direk tot swak gesondheidsuitkomste aanleiding. Die doel van hierdie studie was om die Engelse geletterdheidsvlakke van primêregesondheidsorg-pasiënte deur middel van twee instrumente, naamlik die Learning Ability Battery (LAB) en die aangepasde Rapid Estimate of Adult Literacy, Revised (REALM-R) te assesseer. Daar is voorts ook bepaal hoe die resultate van die aangepaste REALM-R met die LAB korreleer. Data is deur self-rapportering ingesamel, waar die deelnemers vrae uit die LAB-instrument moes beantwoord en spesifieke woorde vir die aangepaste REALM-R hardop te lees. Die data is ontleed deur gebruik te maak van beskrywende en inferensiële statistiek, met inbegrip van 'n chikwadraat-toets en Spearman se rho. Die resultate dui daarop dat die skoolgraad bereik en die leesgeletterdheid van die deelnemers in Suid-Afrika met vier grade verskil. Die korrelasie tussen die resultate van die LAB en die aangepaste REALM-R was $r=0.43(p<0.001)$. $\mathrm{Na}$ gelang van die afsnypunt wat vir die aangepaste REALM-R gebruik word, dui die resultate daarop dat $67 \%$ van die deelnemers lae geletterdheidsvlakke het. Die studie toon die belang van 'n geldige, vinnige instrument vir geletterdheidsifting. Die doeltreffende assessering van pasiënte se geletterdheidsvlakke kan geregistreerde verpleegkundiges help om gesondheidsonderrig op 'n toepaslike vlak aan te bied ten einde pasiënte se gesondheidsgeletterdheid te verbeter.

\section{INTRODUCTION}

\section{Background and rationale}

The most common health education materials used by health care practitioners are in written form. Griffin, McKenna and Tooth (2006:144) believe that in order for health education to be effective, the materials must be written on a level that can be read and understood by all patients. These authors add that the ability to read words and the ability to understand what the words mean are related and that people with low literacy levels therefore have difficulty in understanding health education materials. The limited ability to read and understand health care instructions directly translates into poor health outcomes (Weiss 2007). The relationship between low literacy and adverse health outcomes is represented by two underlying processes. Firstly, low literacy may have a direct negative effect on health due to the barriers to accessing information and using health information. Secondly, low literacy can be a marker for other conditions, such as poverty and lack of access to health care, which may lead to poor health (Pigone, De Walt, Sheridan, Berkman \& Lohr 2005:185).

Pawlak (2005:176) found that health education materials are often written above sixth-grade level. This indicates that health education materials are often written for literate people and therefore marginalise those who cannot read. Health care professionals often overestimate the client's ability to read and comprehend health education and therefore instructions are often not followed due to poor motivation or low literacy. Most clients prefer simple text that is easy to read (Andrus \& Roth 2002:289). It is therefore important to use appropriate literacy assessment tools to assess patients' reading levels (Dreger \& Tremback 2002:281).

Research done in the United States of America (USA), Canada, the United Kingdom and Australia indicates that the average reading level is 4 to 4.6 grades below the last grade completed at school. The mean reading comprehension was at the fifth-grade level (Australian Bureau of Statistics 2006; Davis, Mayeaux, Fredrickson, Jackson \& Murphey 1994:460; Jackson et al. 1991:1172; National Institute for Literacy 2003; Rutherford et al. 2006:235). No such information is available for the South African 
population or the different socio-cultural groups in South Africa. The fact that the literacy levels are not known has far-reaching consequences in terms of health education.

\section{Definition of key concepts}

Adult: An adult is a person who is fully grown and developed; adulthood is the age at which a person has reached maturity (Concise Oxford English Dictionary 2002:18). In this study, an adult refers to a person who is 18 years or older. In terms of Knowles's theory of andragogy (Knowles 1990), adulthood can be categorised as follows:

- biological adulthood is the ability to reproduce

- legal adulthood is defined by the law

- social adulthood is the stage at which adult roles are performed

- psychological adulthood is when self-direction is present.

Low literacy: Low literacy can be defined as the inability to read, write or use numbers effectively (Smith \& Haggerty 2003:409).

Patient: A patient can be described as any person who is ill or is undergoing treatment for disease (Weller 1997:301).

Primary health care sector: According to Naude and Setswe (2000:2), the primary health care sector can be described as all the health care services that a community can use, including clinics and community health care centres.

\section{Objectives}

The purpose of the study was to determine the English reading levels of patients in a primary health care clinic in western Tshwane, Gauteng Province, South Africa and to adapt and validate a suitable literacy instrument to measure the English literacy levels in primary health care patients. This article, however, reports on the second part of the study, carried out with the aim of determining the English literacy levels of primary health care patients using both the Learning Ability Battery (LAB) and the adapted Rapid Estimate of Adult Literacy, Revised (REALM-R) in a clinic in Atteridgeville, in western Tshwane. In addition, the objective was also to determine the correlation between the results of the adapted REALM-R and that of the $\mathrm{LAB}$.

\section{RESEARCH METHOD AND DESIGN}

\section{Research design}

The design for this paper was a cross-sectional survey. According to Bowling and Ebrahim (2005:120), a cross-sectional survey can be described as a measurement of the frequency of a specific attribute, such as a specific exposure, disease or health-related problem in a defined population or a sample population at a certain point in time. Participants are contacted at a fixed time and information is then obtained from them. A cross-sectional survey can also be used to determine the prevalence of healthrelated problems and outcomes and to assess the impact of the health problem

\section{Population and sampling}

The population for this research comprised South African-born adults living in Atteridgeville and attending a specific primary health care clinic selected for the study. The health status of the adults was not taken into consideration in the choice of participants. According to Burns and Grove (2005:263), the target population can be described as the entire set of cases of interest to the researcher. A convenience sampling method was used to select the most conveniently available subjects to participate in the study (Polit \& Beck 2008:341). A total of 100 patients who attended the primary health care clinic in Atteridgeville were approached before or after their consultation to participate in the study. Male and female patients were approached and they had to self-declare that they were able to read. Nath, Sylvester, Yasek and Gunel (2001:859) used a similar sample size to develop the Literacy Assessment for Diabetes instrument.

\section{Data collection}

A self-report (Polit \& Beck 2008:324) was used for data gathering. The LAB and the REALM-R adapted for the South African context were used also used to gather data. To correlate the results of the adapted REALM-R with those of the LAB, the number of each participant was documented and the scores were indicated next to the number to ensure that the results were from the same participant.

The LAB is an instrument used to assess participants' basic schooling and technical abilities. It gives an immediate computer printout of the client's results. The instrument is considered a stable, reliable tool for assessing literacy levels and learning potential (Lead the field n.d.). The LAB is also fully aligned with the principles of the South African Qualifications Authority (SAQA), outcomes-based education and the National Qualifications Framework (NQF) (Learning Ability Battery assessment tool for RPL, PLA \& CASS administrator's manual 2005:8). For the purpose of this study, the school grades were divided into three groups, namely Grades $1-7$, Grades $8-10$ and Grades 11-12. The participants had to answer questions that were posed in the LAB and read the words on the list out loud for the adapted REALM-R. The LAB required participants to complete a standard assessment form that assesses English language comprehension. The assessment form consists of five sections, with each section consisting of 10 English sentences. The participants were instructed to complete the sentence by choosing the correct word in brackets that would complete the sentence so that it made sense. The five sections ranged in difficulty according to school Grade levels 1-12. Each correct answer received one mark, adding to a total mark of 50. The LAB allows the testing of groups consisting of 10-20 participants. The evaluation was done in a private room. The researcher attended a three-day training programme on the use of the $\mathrm{LAB}$ and gained a certification of competency.

The REALM- $\mathrm{R}$ is an instrument designed and validated to identify how well primary health care clients understand words that are commonly used by health care personnel. The REALM-R was designed to identify clients that have potential literacy problems (Bass, Wilson \& Griffith 2003:1037). The REALM-R adapted for the South African context consists of 11 words. During the adapted REALM-R literacy test, participants were required to read the words aloud to a field worker. The words pronounced correctly were then scored according to a phonetic pronunciation key provided to the fieldworker. The field worker was trained to perform the assessment before the actual research was done. Participants were given the following instruction:

'Would you please read aloud as many of the words from the list as you can? Start with the first word. When you come to a word that you cannot read, try your best or say "pass" and go on to the next word.'

The fieldworker had a copy of the list and noted a plus sign $(+)$ after each word that was pronounced correctly, a zero (0) after words that was mispronounced and a minus sign (-) after words not attempted. Self-corrected words were marked $(+)$ and counted. If the participant hesitated for more than five seconds with a word, the field worker said 'pass' and asked the participant to continue with the next word. The pluses were counted and a score out of eight was given. The data gathering for the adapted REALM-R took $2 \mathrm{~min}-3 \mathrm{~min}$ per participant.

\section{Data analysis}

Descriptive and statistical analyses were used to evaluate data. According to Polit and Beck (2008:567), descriptive statistics are used to describe the relationship between variables. Spearman's 
TABLE 1

Learning Ability Battery score (total score $=50, n=100$ )

\begin{tabular}{lll}
\hline Score & $\boldsymbol{n}$ & $\%$ \\
\hline$<10$ & 6 & 6 \\
$11-20$ & 19 & 19 \\
$21-30$ & 44 & 44 \\
$31-40$ & 25 & 25 \\
$41-50$ & 6 & 6 \\
\hline Total & $\mathbf{1 0 0}$ & $\mathbf{1 0 0}$ \\
\hline
\end{tabular}

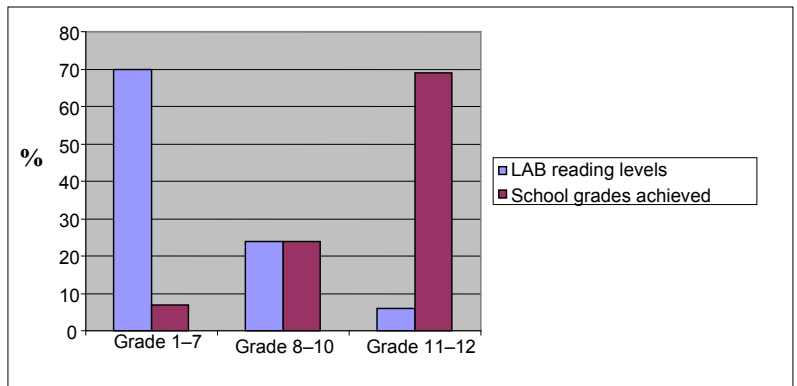

FIGURE 1

Proportion of participants with Grades 1-7, 8-10 and 11-12, according to reported scholastic achievement and reading level as determined by the Learning Ability Battery (LAB)

rho was used to determine the correlation between the results of the adapted REALM-R and that of the LAB. Spearman's rho can be described as the correlation index used for ordinal level measures (Polit \& Beck 2008:571). The chi-square test of independence was performed to test whether two variables being examined were independent or related. The chi-square is distribution-free and may therefore be used with a convenience sample (Burns \& Grove 2005:518).

\section{RESULTS}

\section{Demographic information}

The participants' ages ranged from $18-59$ years, with a mean age of 29.37 years. With regard to achievement of the highest school grades (Grades 11 and 12), 40\% of the participants between the ages of 19 and 29 achieved these grades, followed by $22 \%$ of the participants in the 30- to 39-year age group. The older the participants, the lower the school grades achieved, for example, only $4 \%$ of the participants aged $40-49$ indicated a Grade 11 or 12 level of schooling. The older participants ( $50-59$ years) $(3 \%)$ all indicated a Grade 1-7 level of schooling.

\section{Results of the Learning Ability Battery}

Table 1 indicates the number of participants according to the score obtained for the LAB.

The results indicate that $44 \%$ of the participants scored $21-30$ out of 50 and $25 \%$ of the participants scored $31-40$ out of 50 for the LAB. Only $6 \%$ of the participants had a score of $41-50$ out of 50 for the $\mathrm{LAB}$. The comparative school grades of the $\mathrm{LAB}$ results were obtained after the scores were processed in the computer-based program. The results were then compared to the school grades achieved by the participants. Figure 1 indicates the proportions of participants according to the school grades achieved and the grade at which the participants could actually read according to the results of the $\mathrm{LAB}$.

In Figure 1,69\% of the participants indicated that they had achieved Grade 11 or 12; however, only $6 \%$ of the participants scored a Grade 11-12 reading level on the LAB. On the other side of the continuum, the reading level of $70 \%$ of the participants
TABLE 2

Mean grade according to school grade achieved and Learning Ability Battery reading level achieved

\begin{tabular}{ll}
\hline Reading level & Mean (grade) \\
\hline School grade achieved & 10.73 \\
Learning Ability Battery reading level achieved & 6.75 \\
\hline Difference in means & $\mathbf{4 . 0 ^ { * }}$ \\
\hline *rounded off. &
\end{tabular}

TABLE 3

Score of participants according to Rapid Estimate of Adult Literacy, Revised $(n=100)$

\begin{tabular}{lll}
\hline Score & $\boldsymbol{n}$ & \% \\
\hline 2 & 2 & 2 \\
3 & 5 & 5 \\
4 & 4 & 4 \\
5 & 16 & 16 \\
6 & 14 & 14 \\
7 & 26 & 26 \\
8 & 33 & 33 \\
\hline Total & $\mathbf{1 0 0}$ & $\mathbf{1 0 0}$ \\
\hline
\end{tabular}

was assessed at a Grade 1-7 according to the LAB, although only $7 \%$ indicated a Grade $1-7$ level of schooling achieved $\left(\chi^{2}\right.$ $=61.580 ; p<0.01)$. Table 2 indicates the mean school grade of the participants as well as the reading grade level achieved on the LAB.

From Table 2, it is clear that there is a four-grade difference between the school grade achieved and the LAB reading level.

\section{Results of the adapted Rapid Estimate of Adult Literacy, Revised}

The REALM-R adapted to the South African context consisted of 11 words; however, only eight of the words were scored. Table 3 indicates the participants' scores on the adapted REALM-R.

As indicated in Table 3, 16\% of the participants scored 5 out of 8 , another $14 \%$ scored 6 out of $8,26 \%$ scored 7 out of 8 and only $33 \%$ of the participants could correctly pronounce all the words on the adapted REALM-R.

Correlation of the adapted Rapid Estimate of Adult Literacy, Revised and the Learning Ability

\section{Battery}

The correlation between the two methods is $r=0.43(p<0.001)$. This indicates that the measurements by the two literacy assessment tools are linearly related. Thus, an increase in measurements by the adapted REALM-R implies that the measurements by the LAB will increase and vice versa. The graphical display of this relationship is presented in Figure 2

The $r=0.43$ is the correlation coefficient (Quantitative management 2003:151). This source (2003:151) indicates that if $r$ is $0<r<+1$, then the two variables show a positive linear correlation. As $r=$ 0.43 , this indicates a positive linear correlation between the two variables, namely the adapted REALM-R $(x)$ and the LAB $(y)$. The correlation indicates the degree of strength of the relationship of the two variables (Rice 2007:146)

The coefficient of determination for $r^{2}=0.1849$ (Steyn, Smit, Du Toit \& Strasheim 2000:175). It follows therefore that $18.49 \%$ of the variation in the dependant variable $y$ (LAB) can be explained by the independent variable $x$ (adapted REALM-R) (Steyn et al., 2000:175). This indicates that for $18.49 \%$ the scores of the LAB and the adapted REALM-R correlate directly. 


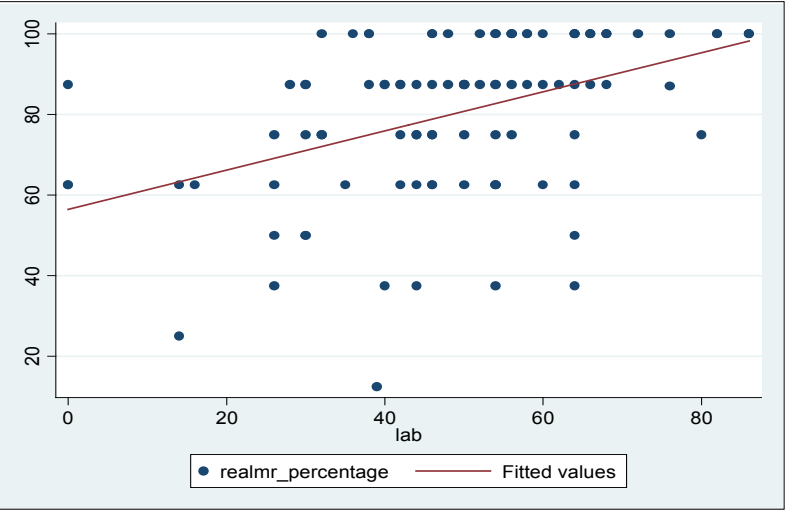

FIGURE 2

Correlation of the Rapid Estimate of Adult Literacy, Revised (REALM-R) and the Learning Ability Battery (LAB)

\section{A South African cut-off point for the Rapid Estimate of Adult Literacy, Revised}

The current cut-off point for the REALM-R for the USA is 6 out of 8 (Feinberg \& Pharmd 2006). The purpose of the REALM-R is not to determine an exact reading grade but to identify a patient who could be at risk for low literacy (Griffin et al. 2006:76). A patient with a score of 6 or below out of 8 is considered at risk for low literacy (Feinberg \& Pharmd 2006).

Less than half $(41 \%)$ of the participants had a score of 6 or less, indicating low literacy, while $59 \%$ of the participants had a score of 7-8 out of 8 . Due to the positive linear correlation found between the adapted REALM-R and the LAB, it is suggested that for South Africa, the cut-off point should be 7 out of 8 . More research, however, is needed to determine a South African cutoff point.

The results of the study indicate that if the cut-off point for the adapted REALM-R is 7 out of $8,67 \%$ of the participants would be identified as having low literacy. This group of participants would not gain knowledge and understanding through conventional health education teaching methods in the primary health care environment. Using the LAB as a reference, $70 \%$ read at a Grade 1-7 level, which corresponds with the $67 \%$ identified with low literacy if a cut-off point of 7 out of 8 is used.

\section{ETHICAL CONSIDERATIONS}

Permission to conduct the study among clients from a clinic in Atteridgeville was obtained from the Ethics Committee of the Tshwane University of Technology (No. 2005/02/008) and the Provincial Department of Health. Informed consent was obtained from the respondents to participate in the study. The participants were informed that they would have to read and complete literacy tools. The fieldworkers were able to answer any questions regarding the study in the participants' own language to ensure full understanding. Data obtained from both literacy assessment tools were kept strictly confidential. The participants were asked to fill in only their age, date of birth and school grade completed on the adapted REALM-R. The participants received a sequential number that was used on both data-gathering instruments.

Participants completed the adapted REALM-R in a private room, to avoid them experiencing psychological discomfort when not being able to read the words. Ten participants were asked to complete the $\mathrm{LAB}$ at a time and were placed in a private room. To ensure privacy, school grade levels and age were not disclosed to anyone except the researcher and the fieldworkers.

\section{VALIDITY AND RELIABILITY}

The REALM-R is validated as a shortened version of the REALM and was designed for use in the public health care sector and primary health care settings to identify patients with low literacy (Davis et al. 1994:461). The REALM-R correlates with a number of other tests, including the SORT-R, WRAT-R, PIAT-R and the TOFHLA (Pawlak 2005:178)

Several measures were used to ensure the validity and reliability of the LAB. The Learning Ability Battery Version 8.3 is an assessment tool for various levels of education for example numerical and mathematical Adult Basic Education and Training levels $0-4$, school Grades $1-12$, NQF $1-4$ and recognition of prior learning, trainability and competency levels for entry levels to learnership. The instrument is accredited and supported by SAQA and the NQF and acknowledged by the Service Sector Education and Training Authority (SETA accreditation number E.T.D.P-581-PE-250105F000184 on 25 January 2005).

In terms of the adapted REALM-R, face and content validity was ensured through the validation panel. Several experts in the field of reading and primary health care were used to evaluate the instrument. The number of words and syllables for the REALM-R adapted for the South African context remained unchanged; only the words were adapted for the South African context. The cultural-linguistic fit was not validated due to the multicultural nature of the South African society and due to the fact that health-promotion materials written in English are not written for a specific target culture, but with the aim of being read and understood in the multicultural environment of primary health care.

\section{DISCUSSION}

\section{The Learning Ability Battery}

The LAB is generally used to assist human resource managers, trainers, facilitators and assessors to identify a person's current level of learning potential (Learning Ability Battery assessment tool for RPL, PLA \& CASS administrator's manual 2005:3). The LAB was developed to assess a number of abilities of a person, including word recognition and reading comprehension (2005:4). The LAB also assesses NQF levels, which indicate certain basic scholastic and technical achievements. The LAB is used by employers to assess employees' learning potential and identify them as illiterate, semi-literate or literate (2005:4).

Osborn (2007) indicates that the main language used for linguistic communication is English. The preferred business language in South Africa is also English. The LAB was therefore used in the study to assess the English reading and comprehension levels of patients in a primary health care clinic in the west of Tshwane. The advantages of using the LAB for the purposes of this study included the fact that the LAB is a stable, reliable tool and useful as a reference point to assess the grade at which participants read and comprehend English (Learning Ability Battery assessment tool for RPL, PLA E CASS administrator's manual 2005). The results are processed quickly and it is relatively easy to administer.

The LAB, though suitable in a research situation, would, however, not be appropriate for the primary health care context. Several aspects were identified that make the tool impractical for use in a primary health care setting. One of the disadvantages is that it is a computer-based program requiring specialised training, which would be both time-consuming and expensive.

\section{The Rapid Estimate of Adult Literacy, Revised}

For the purposes of the study, the existing REALM-R was adapted for the South African context. The advantages of this test in assessing patients' literacy levels in a primary health care 
clinic are that the REALM-R is easy to administer and takes only two to three minutes, while minimal training of health care professionals in administering the tool is required. If the patients' literacy levels can be assessed before or during their consultation, the registered professional nurses will be able to adapt their health education strategies immediately and teach the patients on a level where learning can actually take place. The REALM-R is paper-based and no computer skills or any other particular skills are needed.

The cut-off point identified (Feinberg \& Pharmd 2006) for the original REALM-R is a score of 6 out of 8 . Patients with a score of 6 out of 8 or less are identified as low literate. The findings indicate that if the cut-off point for the adapted REALM-R is a score of 6 and below, $41 \%$ of the participants would be illiterate. Thus the suitability of the cut-off point for the adapted REALM-R for the South African context is questioned. It is therefore suggested that the cut-off point of the adapted REALM-R be a score of 7 out of 8 or below. If the cut-off point is a score of 7 or below, $67 \%$ of the participants would be illiterate or have low literacy skills. The percentage of $67 \%$ is more in line with the results of the LAB, but more research is needed to validate these suggestions.

The REALM-R only measures word recognition and word pronunciation, while the LAB measures word recognition and comprehension. A comparison of the results of the adapted REALM-R and that of the LAB indicate that the results of the adapted REALM-R are relatively high (if the cut-off point is at 6 out of 8 and below), and the results of the LAB are relatively low. It can be assumed that the participants were able to recognise and pronounce the words in the adapted REALM-R but struggled to comprehend the meaning of the words. The participants may be able to recognise the words used in health education materials but may have difficulty in comprehending the meaning of the message given. Although word recognition tests do not measure comprehension directly, low word recognition scores suggest low comprehension, since comprehension is a higherorder skill. Word recognition tests are quick and easy to score and are appropriate for low-level readers (Nath et al. 2001:858). Further research to determine the appropriate cut-off point for the adapted REALM-R for the South African context is therefore needed.

\section{The correlation of the adapted Rapid Estimate of Adult Literacy, Revised and the Learning Ability Battery}

A correlation of the adapted REALM-R and the LAB could be determined in the study. Figure 2 indicates a positive linear correlation between the results of the adapted REALM-R and that of the LAB. The results of the adapted REALM-R show that $18.49 \%$ are directly influenced by the factors measured by the $\mathrm{LAB}$, which indicates that for $18.49 \%$ of the time, the results of the adapted REALM-R are due to poor word recognition and language comprehension identified by the LAB. The results for the other $81.51 \%$ of the time could be due to the determinants of health literacy as identified by Pawlak (2005:175). These influences allow opportunity for future research.

\section{School grade level and reading ability}

Doak, Doak and Root (1996:2) mention that, until recently, literacy levels and reading levels were internationally measured in terms of school grade levels. This means that if a person had achieved Grade 5, the person was presumed to be able to read at Grade 5 level and was therefore literate. However, Andrus and Roth (2002:282) state that although a person's reading ability is a useful indicator of the person's literacy level, the reading ability cannot be directly linked to a person's school grade level as previously measured. Doak et al. (1996:2), as well as Cotungna, Viekery and Carpenter-Haefele (2005:213), state that literacy levels and school grade levels are measured differently and that there is no direct conversion between the two. A person's grade level is not an accurate indication of reading ability.

The consequences of low literacy are indicated by Weiss (2007:13). This author indicates that patients with low literacy have less knowledge of preventative health care services and medical conditions and have poorer health status. Weiss (2007:14) also indicates that patients with low literacy are more likely to be hospitalised, resulting in increased health care costs for the health care system. The consequences of low literacy are a direct result of low literacy levels and poor reading ability (Pigone et al. 2005:185).

\section{CONCLUSION}

The first step to improve health is to improve literacy levels. Attaining higher literacy levels or teaching patients at their literacy level will lead to patients becoming informed consumers of health care services. In addition, the level of care will be matched with the need of the patient and therefore treatment compliance by the patient will improve. Improving the health of all will lead to a reduction in health disparities and the improved health of the South African population.

\section{LIMITATIONS}

The study was conducted in only one primary health care clinic in an urban area. The patients participating in the study were mainly Sepedi- and Setswana-speaking. Due to the convenience sample, the results may not be generalisable to a larger context. In addition, the sample size was only 100 participants, thus a larger study should be conducted to validate the results of this study.

\section{RECOMMENDATIONS}

In terms of nursing practice, health care professionals should be literacy-orientated. In this way they will provide appropriate health education that will benefit the patient and improve the health literacy of patients. Because patients with low literacy or those who are illiterate have difficulty in understanding health care information, health care professionals should educate patients on their level of literacy. Once an appropriate literacy tool for South Africa becomes available, patients' literacy levels must be determined before health education is provided to ensure understanding of the content. Because the adapted REALM-R is quick and easy to use, the registered nurse would be able to assess patients' literacy level before providing health education. In addition, to assist the registered professional nurse, alternative ways of presenting information that are culturally sensitive and age-appropriate must be researched and developed for use in the primary health care setting. Research should also be conducted to evaluate the influence of different socio-cultural backgrounds on the effectiveness of the adapted REALM-R as well as how the assessment of all patients' literacy levels could be achieved efficiently in a primary health care clinic. The REALM-R requires no computer assistance and therefore the registered nurse would be able to easily assess patients' literacy level before educating them.

Research should be conducted to investigate the readability of health education materials used to educate patients in the primary health care setting. In addition, evaluation research should be carried out to determine the usefulness of the printed material in educating patients with low literacy or those who are illiterate. Further research using other contexts throughout South Africa is needed to provide representative results, in terms of both the literacy levels and the further validation of the adapted REALM-R compared to the LAB. The cut-off level of the REALM-R in the South African context must be finalised to provide the health care sector with an easily managed literacy tool for application in the primary health care sector. 


\section{REFERENCES}

Andrus, R.M. \& Roth, M.T., 2002, 'Health literacy: A review', Pharmacotherapy 22(3), 282-302.

Australian Bureau of Statistics, 2006, Adult literacy and life skills survey, summary results, Australia, viewed 02 March 2008, from http://www.abs.gov.au/austats/

Bass, P.F., Wilson, J.F. \& Griffith, C.H., 2003, 'A shortened instrument for literacy screening', Journal of General Internal Medicine 18(12)Dec, 1036-1038.

Bowling, A. \& Ebrahim, S., 2005, Handbook of health research methods: Investigating, measurement and analysis, Open University Press, Berkshire.

Burns, N. \& Grove, S.K., 2005, The practice of nursing research, conduct, critique and utilization, 5th edn., Saunders, Philadelphia.

Concise English Oxford dictionary, 2002, 10th edn., Oxford University Press, London.

Cotugna, N., Vickery, C.E. \& Carpenter-Haefele, K.M., 2005, 'Evaluation of literacy levels of patient education pages in health-related journals', Journal of Community Health 30(3), 213-219.

Davis, T.C., Mayeaux, E.J., Fredrickson, J.A., Jackson, R.H. \& Murphy, P.W., 1994, 'Reading ability of parents compared with reading levels of paediatric patient education materials', Paediatrics 93, 460-468.

Doak, C.C., Doak, L.G. \& Root. J.H., 1996, Teaching patients with low literacy skills, 2nd edn., Lippincott Williams \& Wilkins, Philadelphia.

Dreger, V. \& Tremback, T., 2002, 'Optimize patient health by treating literacy and language barriers', Association of Operating Room Nurses 75(2), 280-293.

Feinberg, J.L. \& Pharmd, J.D., 2006, Adult medication: Improving medication adherence in older adults, viewed 12 February 2007, from http://www.adultmeducation.com

Griffin, J., McKenna, K. \& Tooth, L., 2006, 'Discrepancy between older clients' ability to read and comprehend the reading level of written educational materials used by occupational therapists', British Journal of Occupational Therapy 69(3), 144-145.

Jackson, R.H., Davis, T.C., Bairnsfather, L.E., George, R.B., Crouch, M.A. \& Gault, H., 1991, 'Patient reading ability: An overlooked problem in health care', Southern Medical Journal 84(10), 1172-1175.

Knowles, M., 1990, Knowles's Andragogy, viewed 26 May 2007, from http://www.learningandteaching.info.htm
Lead the field n.d., Introduction to learning ability battery (LAB), viewed 12 July 2007, from http://www.leadthefield.co.za/

Learning Ability Battery assessment tool for RPL, PLA E CASS administrator's manual, 2005, 8th edn., Lead the field, Ferndale.

Modified Delphi technique, n.d., viewed 27 July 2008, from http:// www.communitydevelopment.uiuc.edu/

Nath, C.R., Sylvester, S.T., Yasek, V. \& Gunel, E., 2001, 'Development and validation of a literacy tool for persons with diabetes', The Diabetes Educator 27(6), 857-864.

National Institute for Literacy, 2003, Literacy in the United States, viewed 02 March 2008, from http://www.nifl.gov

Naude, M. \& Sewetse, G., 2000, Basic community health nursing Heinemann, Sandton.

Osborn, D., 2007, Language policy and language use in South Africa: An uneasy marriage, viewed 12 January 2009, from http:// www.mailarchive.com/africanlanguages@yahoogroups. com/msg00524.html

Pawlak, R., 2005, 'Economic considerations of health literacy', Nursing Economics 2(4), 173-180.

Pigone, M., De Walt, A.D., Sheridan, S., Berkman, N. \& Lohr, K.N., 2005, 'Interventions to improve health outcomes for patients with low literacy: A systemic review', Journal of General Internal Medicine 20(2), 185-192.

Polit, F.D. \& Beck, C.T., 2008, Nursing research: Generating and assessing evidence for nursing practice, 8th edn., Lippincott Williams \& Wilkins, Philadelphia.

Quantitative management: Introduction to the business world, 2003, University of South Africa, Pretoria.

Rice, J.A., 2007, Mathematical statistics and data analysis, 3rd edn., University of California, Duxbury.

Rutherford, J., Holman, R., Macdonald, J., Taylor, A., Jarrett, D., \& Bigrigg, A., 2006, 'Low literacy: A hidden problem in family planning clinics', Journal of Family Planning and Reproductive Health Care 32(4), 235-240.

Smith, J.L. \& Haggerty, J., 2003, 'Literacy in primary care population: Is it a problem?', Canadian Journal of Public Health 94(6), 408-412.

South Africa n.d., Townships South Africa: Atteridgevilel/Saulsville, viewed 02 March 2008, from http://www.saweb.co.za

Steyn, A.G.W., Smit, C.F., Du Toit, S.H.C. \& Strasheim, C., 2000, Modern statistics in practice, Van Schaik, Pretoria.

Weiss, B.D., 2007, Health literacy and patient safety: Help patients understand, viewed 28 December 2008, from http://www. medscape.com/viewarticle/566053_4

Weller, F.B., 1997, Bailliere's nurses dictionary, 22nd edn., Bailliere, Philadelphia. 